\title{
Research
}

\section{Systolic inter-arm blood pressure difference and risk of cognitive decline in older people:}

\author{
a cohort study
}

\begin{abstract}
Background

Systolic inter-arm difference in blood pressure (IAD) and cognitive decline are both associated with cardiovascular disease; therefore, it was hypothesised that IAD may be predictive of cognitive decline.
\end{abstract}

\section{Aim}

To examine associations of IAD with cognitive decline in a community population.

\section{Design and setting}

A prospective study of older Italian adults enrolled in the InCHIANTI study.

\section{Method}

Univariable and multivariable associations of IAD were explored with declines in mini mental state examination (MMSE) scores, Trail Making Test $A$ and $B$ scores, and a composite outcome representing substantial decline in any of these scores. Backward stepwise regression was used to adjust observed associations of IAD with cognitive decline.

\section{Results}

The rate of decline for MMSE scores in 1133 participants was greater with $I A D \geq 5 \mathrm{mmHg}$ or $\geq 10 \mathrm{mmHg}$. On univariable analyses continuous IAD was associated with the composite outcome lodds ratio [OR] 1.16 per $5 \mathrm{mmHg}$ of $\mid A D, 95 \%$ confidence interval $[C l]=1.02$ to 1.31 ] Substantial decline in MMSE score was seen with IAD $\geq 5 \mathrm{mmHg}$ lOR $1.41,95 \% \mathrm{Cl}=1.03$ to 1.93 ), and in the composite outcome with IAD $\geq 5 \mathrm{mmHg}$ lOR $1.44,95 \% \mathrm{Cl}=1.10$ to

1.89) or $\geq 10 \mathrm{mmHg}$ lOR $1.39,95 \% \mathrm{Cl}=1.03$ to 1.88). After multivariable adjustment, an IAD $\geq 5 \mathrm{mmHg}$ remained associated with reductions in the composite outcome, reflecting declining cognitive performance $\operatorname{lOR} 1.46,95 \% \mathrm{Cl}=1.05$ to 2.03

\section{Conclusion}

An IAD $\geq 5 \mathrm{mmHg}$ is associated with cognitive decline in a representative older population.

Given that systolic inter-arm differences in blood pressure are easily measured, confirmation of these findings could inform individualised treatment for the prevention of cognitive decline and dementia.

\section{Keywords}

aged; blood pressure; cognitive dysfunction cohort studies; dementia; older people.

\section{INTRODUCTION}

Hypertension and dementia are both associated with older age and with each other.' Globally, the numbers of people living with dementia are predicted to rise, representing substantial and increasing costs and care burdens for society. ${ }^{2,3}$ The risks of developing dementia are associated with known risk markers for cardiovascular disease, such as mid-life hypertension, ${ }^{4,5}$ diabetes, ${ }^{6}$ and a widening pulse pressure. ${ }^{7}$

A difference in systolic blood pressures between arms, referred to as inter-arm difference (IAD), has also been shown to be associated with increased risk of cardiovascular morbidity and mortality, and is associated with increasing pulse pressure and arterial stiffness., 8 An IAD $\geq 10 \mathrm{mmHg}$ is found in $11 \%$ of people with hypertension and $7 \%$ of those with diabetes. ${ }^{10}$ The precise aetiology of an IAD is incompletely established; however, arterial changes seem to be a common contributor. ${ }^{11}$ A body of evidence now exists to support recognition of IAD as an early marker for subsequent vascular disease, and to quantify that risk for cardiovascular events. ${ }^{12,13}$

Preclinical vascular damage can be observed early in the course of hypertension, ${ }^{14}$ whereas measurable

CE Clark, PhD, FRCP, FRCGP, senior clinical lecturer in primary care; D Thomas, MPH, MRCGP, honorary clinical associate research fellow; JL Campbell, MBE, MD, FRCGP, professor of general practice and primary care, Primary Care Research Group, Institute of Health Research, University of Exeter Medical School, UK. DJ Llewellyn, PhD, associate professor of neuroepidemiology and digital health, Mental Health Research Group, Institute of Health Research, University of Exeter Medical School, UK: the Alan Turing Institute, British Library, London, UK. L Ferrucci, MD, PhD, scientific director, National Institute on Aging, Baltimore, MD, US S Bandinelli, MD, InCHIANTI study coordinator, Geriatric Unit, Local Health Unit Tuscany Centre, Florence, Italy. cognitive decline or a diagnosis of dementia are later consequences of exposure to raised blood pressure. ${ }^{5,15}$ White matter lesions predict the onset of dementia; ${ }^{16}$ their progression is slowed when hypertension is controlled, and antihypertensive treatment is associated with a reduced risk of subsequent Alzheimer's disease. ${ }^{17,18}$ Results of a 2019 study suggest that intensive blood pressure lowering may prevent progression of cognitive impairment. ${ }^{19}$ Therefore, prediction of those most at risk of future progression of white matter lesions and cognitive decline is desirable in order to target or intensify treatment for them appropriately. ${ }^{20}$

As a result, IAD may also have a prognostic association with future cognitive decline. To the authors' knowledge, this association has only to date been reported for a subgroup of the Framingham Heart Study cohort who possess the apolipoprotein E $\varepsilon 4$ allele, and was not observed for the overall study population. ${ }^{21}$ If adults with an IAD are shown to be at risk of greater cognitive decline than those without, then IAD measurement in clinical practice could help to differentiate those people with the most to gain from early interventions and intensive blood pressure lowering. The analyses presented in this study were undertaken using data

\section{Address for correspondence}

Christopher E Clark, Primary Care Research

Group, Institute of Health Research, University of Exeter Medical School, Smeall Building, St Luke's Campus, Magdalen Road, Exeter EX1 2LU, UK.

Email: c.e.clarkdexeter.ac.uk

Achrisellesclark

Submitted: 6 September 2019; Editor's response: 25 October 2019; final acceptance:

8 November 2019.

\section{@British Journal of General Practice}

This is the full-length article (published online 5 May 2020) of an abridged version published in print. Cite this version as: Br J Gen Pract 2020; DOI: https://doi.org/10.3399/bjgp20X709589 


\section{How this fits in}

Systolic inter-arm difference in blood pressure (IAD) is associated with increased cardiovascular and all-cause mortality. Cognitive decline is associated with hypertension and cerebrovascular disease, and may be mitigated by aggressive blood pressure lowering in those most at risk. Detection of an IAD may identify individuals at excess risk of cognitive decline. This study found initial evidence that systolic inter-arm differences $\geq 5 \mathrm{mmHg}$ or $\geq 10 \mathrm{mmHg}$ are associated with markers of cognitive decline over a median 9-year follow-up period. Recognition of IAD as a risk marker for cognitive decline may help to inform personalised discussion of blood pressure lowering and other preventive strategies in reducing the risk of cognitive decline.

from the Invecchiare in Chianti (InCHIANTI) study, ${ }^{22}$ a well-documented prospective cohort study of older community living adults, to explore the associations of IAD with cognitive decline.

\section{METHOD}

\section{Population and setting}

The InCHIANTI study is a population-based cohort study of older adults based in Greve in Chianti and Bagno a Ripoli in Italy. In total, 1270 participants aged $\geq 65$ years were recruited from a random sample of city registers between August 1998 and March 2000. Recruitment was designed to be representative of the older Chianti population, with oversampling of those aged $\geq 90$ years to ensure representation of the oldest within the cohort. At least 30 individuals for each decade of age from 20 years old to 64 years old were also recruited to achieve a total of 1453 . Followup has been carried out every 3 years for up to 13 years. Participants all gave informed consent. ${ }^{22}$ The InCHIANTI datasets are available on application with a research proposal to the InCHIANTI investigators (http://inchiantistudy.net/wp).

\section{Outcome measures}

At recruitment and at each 3-yearly followup, cognitive function was assessed by administration of the 30-point mini mental state examination (MMSE); executive functioning was assessed using Trail Making Tests A and B with a 300-second time limit.23,24 The latest follow-up data before censorship were used to examine changes in cognitive measures from baseline, adjusting for length of follow-up.
Substantial cognitive decline was defined for each test as follows: a reduction in MMSE score of $\geq 5$ points from baseline; being in the worst $10 \%$ of decliners from baseline in Trail Making Test A or B; or failure to complete these tests in the time allowed. ${ }^{25-27}$ A composite outcome was also examined, based on the method of Espeland et al, ${ }^{28}$ whereby cognitive decline was defined by any one of the substantial cognitive decline criteria for the MMSE, or Trail Making Test A or B described above.

During recruitment medical examination, blood pressure was measured with subjects resting supine using a standard mercury sphygmomanometer. The sequence of measurements was right arm first, then a 2-minute pause, then the left arm. Two further measurements were subsequently carried out on the higher reading arm. IAD was calculated as right minus left from the paired first measurements. Systolic and diastolic blood pressures were defined as the mean of the second and third measurements. All blood pressure measurements were taken from the initial baseline recruitment examinations.

\section{Statistical analysis}

It was planned a priori to adjust analyses for covariates known to be associated with vascular disease, IAD, or cognitive decline. Specifically, these were age, sex, baseline MMSE score, years of education, systolic and diastolic blood pressure, hypercholesterolaemia (defined as total cholesterol $\geq 5.0 \mathrm{mmol} / \mathrm{L}$ ), current smoking status, diabetes (defined as any of recorded medical history of diabetes, use of medication for diabetes, or fasting glucose of $7.0 \mathrm{mmol} / \mathrm{L}$ at baseline), established vascular disease (defined as medical history of myocardial infarction, angina, or peripheral arterial disease at baseline; ankle-brachial pressure index $<0.9$ or carotid artery stenosis $>40 \%$ on clinical assessment), cerebrovascular disease (defined as medical history or clinical examination suggestive of previous stroke or transient ischaemic attack), body mass index, and length of time in study.

Continuous and discrete variables were compared according to IAD using t-tests and $\chi^{2}$ tests as appropriate. Non-normally distributed continuous data were compared using Mann-Whitney U-tests. Changes of cognitive test scores and (to adjust for varied follow-up lengths) rates of change of cognitive scores were compared by dichotomous IAD cut-offs. Univariable and multivariable associations of absolute IAD were then explored as both a continuous 


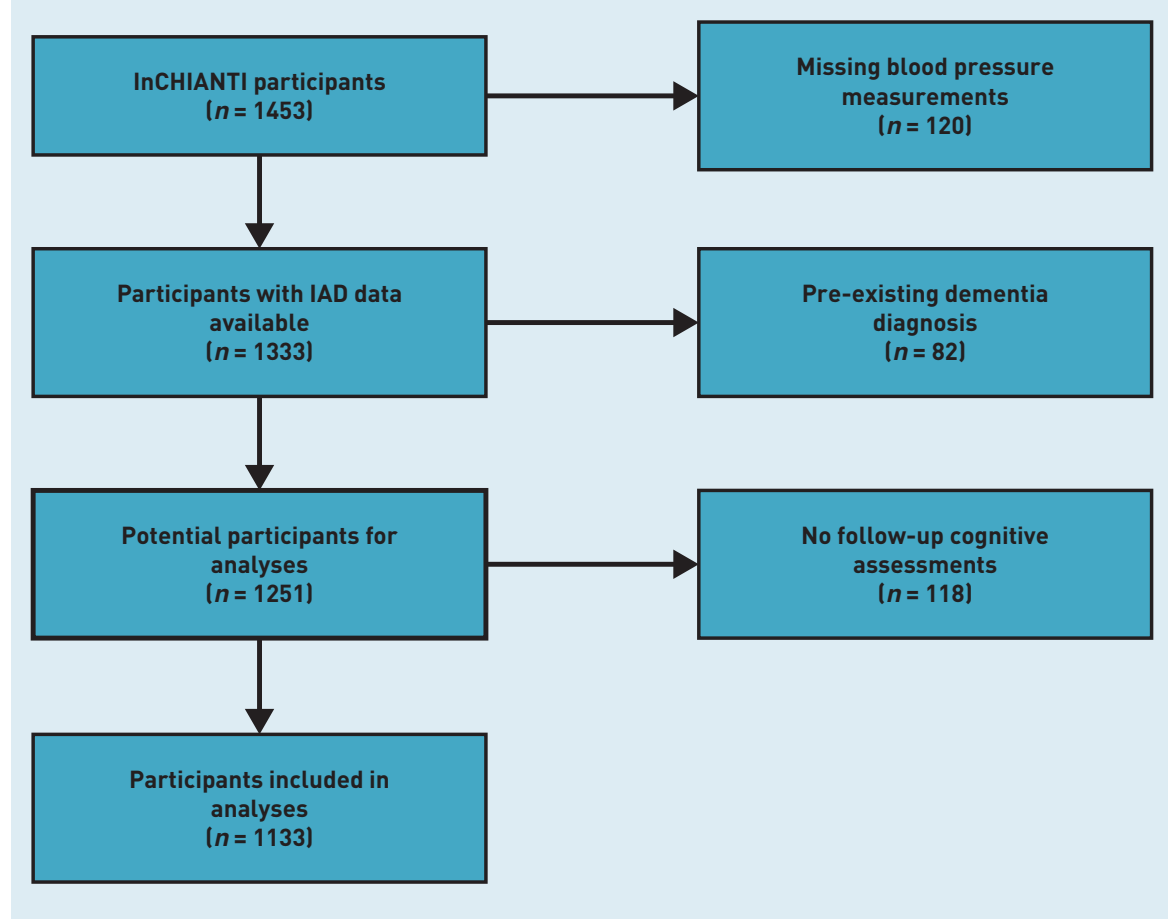

Figure 1. Flow chart for participants eligible for the study. IAD = systolic inter-arm blood pressure difference. variable, and as a dichotomous variable, with substantial cognitive decline using logistic regression modelling. For dichotomous IAD, IAD cut-offs of $\geq 5 \mathrm{mmHg}$ and $\geq 10 \mathrm{mmHg}$ were adopted throughout for consistency with existing literature. ${ }^{29}$ Examination of the commonly quoted IAD $\geq 15 \mathrm{mmHg}$ threshold was planned a prior

\section{Table 1. Differences between eligible participants with and without follow-up data}

\begin{tabular}{|c|c|c|c|}
\hline Variable $^{a}$ & Included ( $n=1133$ ) & Excluded $(n=118)$ & $P$-value \\
\hline Age, years & 66.4 (15.3) & $78.2(11.7)$ & $<0.001$ \\
\hline Female, $n(\%)$ & $621(54.8)$ & $64(54.2)$ & 0.905 \\
\hline Current smokers, $n(\%)$ & 218 (19.2) & $17(14.4)$ & 0.201 \\
\hline Body mass index & $27.2(4.1)$ & $27.5(4.3)$ & 0.478 \\
\hline Baseline MMSE score ${ }^{b}$ & 26.3 (25 to 29) & 23.2 (21 to 27 ) & $<0.001$ \\
\hline Years in education ${ }^{b}$ & 6.8 (5 to 8 ) & 5.0 (3 to 5) & $<0.001$ \\
\hline Years of follow-up & $8.1(1.5)$ & $2.9(2.5)$ & $<0.001$ \\
\hline Systolic blood pressure & $145.6(21.4)$ & $152.2(23.7)$ & 0.002 \\
\hline Diastolic blood pressure & $83.1(9.5)$ & $83.9(9.3)$ & 0.345 \\
\hline $\mathrm{IAD} \geq 10 \mathrm{mmHg}$ & $2.4(4.8)$ & $2.7(7.8)$ & 0.564 \\
\hline Hypertension, $n(\%)$ & 834 (73.6) & $94(79.7)$ & 0.153 \\
\hline Diabetes, $n(\%)$ & $143(12.6)$ & $15(12.7)$ & 0.978 \\
\hline Vascular disease, $n(\%)$ & $177(15.6)$ & $36(30.5)$ & $<0.001$ \\
\hline Cerebrovascular disease, $n(\%)$ & $49(4.3)$ & $18(15.3)$ & $<0.001$ \\
\hline
\end{tabular}

but is not presented because of a low prevalence of participants meeting this magnitude of IAD

Unadjusted odds ratios (ORs) of substantial cognitive decline were calculated for each cognitive test separately and for the composite measure according to IAD. Multivariable associations of IAD were explored, adjusting for the covariates listed above with cognitive measures that showed significant univariable association with IAD using backward stepwise regression. The threshold for inclusion of covariates in multivariable modelling was set at $P<0.2$. The final adjusted model was used to derive adjusted ORs for cognitive decline according to IAD. Terms for age, sex, and systolic blood pressure were retained, irrespective of $P$-value, on aetiological grounds.

$P$-values were two-sided throughout. All analyses were performed using Stata (version 14).

\section{RESULTS}

There were 1453 participants in the InCHIANTI study cohort. After excluding participants missing blood pressure measurements, and those with a preexisting diagnosis of dementia, there were 1251 participants eligible for analysis. Of these, 118 lacked any follow-up data for cognitive tests; therefore, all analyses were based on the remaining 1133 participants (Figure 1). Median follow-up was 9.0 years (interquartile range 8.2 to 9.2 years). Within the cohort follow-up measurements existed for MMSE in 1118 (98.7\%), Trail Making Test A in 933 (82.3\%), and Trail Making Test B in 657 (58.0\%) participants. Those without follow-up records, in comparison with those contributing to the analyses, were older, had higher rates of vascular and cerebrovascular disease, and had lower baseline MMSE scores and years of completed education than participants included in the analyses (Table 1).

Mean systolic blood pressure at recruitment was $145.6 \mathrm{mmHg}$ (standard deviation 21.4) with evidence of rounding to zero (Figure 2). Of the 1133 participants, 277 people $(24.5 \%)$ had an IAD $\geq 5 \mathrm{mmHg}$. Of this 277, $212(76.5 \%)$ had an IAD $\geq 10 \mathrm{mmHg}$, and $30(10.8 \%)$ had an IAD $\geq 15 \mathrm{mmHg}$. Compared with those with an IAD $<10 \mathrm{mmHg}$, those with an IAD above this threshold had lower baseline scores for MMSE, and longer Trail Making Tests $A$ and $B$ times; they were also older and completed fewer years of follow-up. Blood pressures and the rate of hypertension were higher in association with an IAD (Table 2). 


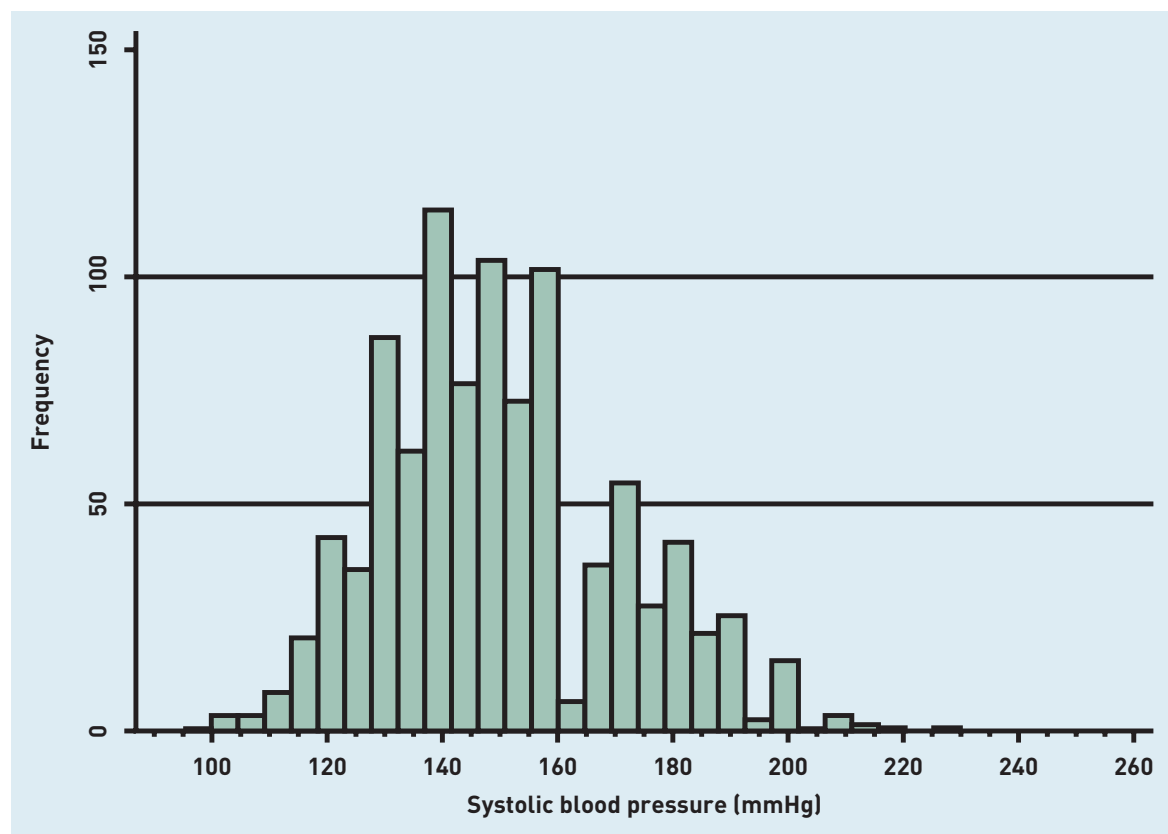

Figure 2. Distribution of systolic blood pressure at recruitment.

\section{Table 2. Characteristics of participants according to systolic inter- arm blood pressure difference (IAD) by IAD status $\geq 10 \mathrm{mmHg}$ or $<10 \mathrm{mmHg}$}

\begin{tabular}{|c|c|c|c|}
\hline Variable $^{\mathrm{a}}$ & $I A D \geq 10 \mathrm{mmHg}(n=212)$ & $I A D<10 \mathrm{mmHg}(n=921)$ & $P$-value \\
\hline Age, years & $69.3(12.9)$ & $65.7(15.7)$ & 0.003 \\
\hline Female, $n(\%)$ & 117 (55.2) & 504 (54.7) & 0.902 \\
\hline Current smokers, $n(\%)$ & $38(17.9)$ & 180 (19.5) & 0.590 \\
\hline Body mass index & $26.8(16.2)$ & $27.2(27.0)$ & 0.210 \\
\hline Baseline MMSE score ${ }^{b}$ & 26 (24 to 28 ) & 27 (25 to 29 ) & 0.025 \\
\hline Baseline Trails A score $^{b}$ & $76(46$ to 118$)$ & $65(41$ to 102$)$ & 0.003 \\
\hline Baseline Trails B score ${ }^{b}$ & 157 (98 to 246 ) & 138 (84 to 227) & 0.026 \\
\hline Years in education ${ }^{b}$ & $5(4$ to 8$)$ & $5(5$ to 8$)$ & 0.167 \\
\hline Years of follow-up & $7.8(7.6)$ & $8.2(8.1)$ & 0.006 \\
\hline Systolic blood pressure & $158.2(20.9)$ & $142.6(20.5)$ & $<0.001$ \\
\hline Diastolic blood pressure & $87.0(9.0)$ & $82.1(9.3)$ & $<0.001$ \\
\hline Hypertension, $n(\%)$ & 187 (88.2) & 647 (70.3) & $<0.001$ \\
\hline Diabetes, $n(\%)$ & $31(14.6)$ & 112 (12.2) & 0.330 \\
\hline Vascular disease, $n[\%]$ & $30(14.2)$ & $147(16.0)$ & 0.513 \\
\hline Cerebrovascular disease, $n(\%)$ & $11(5.2)$ & $38(4.1)$ & 0.493 \\
\hline
\end{tabular}

$5 \mathrm{mmHg}$ of $\mid \mathrm{AD}, 95 \% \mathrm{Cl}=1.02$ to 1.31 , $P=0.021$ ). Using dichotomised terms for $I A D$, the odds of substantial decline in the MMSE score were greater with an IAD $\geq 5 \mathrm{mmHg}$ lOR $1.41,95 \% \mathrm{Cl}=1.03$ to 1.93 , $P=0.032$ ), and in the composite score with an $\mid A D \geq 5 \mathrm{mmHg}$ (OR 1.44, 95\% Cl = 1.10 to $1.89, P=0.009$ ) or $\mid A D \geq 10 \mathrm{mmHg}$ (OR $1.39,95 \% \mathrm{Cl}=1.03$ to $1.88, P=0.030$ ). No difference was evident for Trail Making Tests (Table 4).

Given no findings of univariable associations between Trail Making Tests and IAD, multivariable modelling was only undertaken to explore substantial decline in MMSE scores and in the composite scores. Multivariable models were derived, to which IAD was added to calculate adjusted ORs for associations of IAD with cognitive measures. Variables retaining significance in either model were age, sex, baseline MMSE, years in education, diabetes, previous cerebrovascular event, and duration of follow-up (Table 5). These models, with inclusion of systolic blood pressure as planned, were used to adjust univariable associations of IAD for all variables (Table 4). After adjustment, continuous IAD was no longer associated with any of the outcomes. For dichotomous IAD cut-offs, only an IAD $\geq 5 \mathrm{mmHg}$ remained associated with increased odds of decline in the composite outcome (OR $1.46,95 \% \mathrm{Cl}=1.05$ to 2.03 , $P=0.026)$.

\section{DISCUSSION}

\section{Summary}

In this cohort, representative of the older Italian population, an IAD $\geq 5 \mathrm{mmHg}$ was observed to be associated with a decline of $\geq 5$ points in the MMSE score over a median 9 -year follow-up period. When a composite score also taking account of a decline in Trail Making Tests was considered, this association was also observed for an IAD $\geq 10 \mathrm{mmHg}$, and as a continuous variable. After adjustment in a multivariable model, the composite outcome remains more likely to be achieved with an $I A D \geq 5 \mathrm{mmHg}$.

\section{Strengths and limitations}

This study achieved high retention and follow-up rates over almost a decade, allowing longitudinal study of clinically meaningful changes. The availability of a large number of baseline variables permitted robust adjustment of findings, although completion rates for follow-up Trail Making Tests were lower than for the MMSE, so may have constrained the ability to demonstrate changes in these outcomes. The MMSE examination also has 
Table 3. Changes in cognitive scores according to systolic inter-arm blood pressure difference

\begin{tabular}{|c|c|c|c|c|c|c|}
\hline Cognitive score & $\begin{array}{c}\mid A D<5 \mathrm{mmHg}, \\
n(95 \% \mathrm{Cl})\end{array}$ & $\begin{array}{c}\mathrm{IAD} \geq 5 \mathrm{mmHg}, \\
n(95 \% \mathrm{Cl})\end{array}$ & $P$-value & $\begin{array}{c}\text { IAD }<10 \mathrm{mmHg} \\
n(95 \% \mathrm{Cl})\end{array}$ & $\begin{array}{c}I A D \geq 10 \mathrm{mmHg}, \\
n(95 \% \mathrm{Cl})\end{array}$ & $P$-value \\
\hline Change in MMSE score, units & $2.17(1.78$ to 2.56$)$ & 2.91 (2.08 to 3.73 ) & 0.084 & 2.25 (1.86 to 2.63 ) & 2.80 (1.89 to 3.72 ) & 0.237 \\
\hline Rate of change MMSE score ${ }^{a}$ & 0.29 (0.24 to 0.35$)$ & 0.45 (0.32 to 0.58$)$ & 0.012 & 0.31 (0.25 to 0.36$)$ & 0.44 (0.29 to 0.59 ) & 0.052 \\
\hline Change in Trails A score, seconds & 5.55 (2.47 to 8.63$)$ & $5.68(-1.35$ to 12.70$)$ & 0.970 & 5.77 (2.74 to 8.79$)$ & $4.68(-3.53$ to 12.90$)$ & 0.779 \\
\hline Rate of change Trails A score ${ }^{a}$ & 0.75 (0.36 to 1.13 ) & $0.62(-0.28$ to 1.52$)$ & 0.780 & 0.79 (0.39 to 1.16$)$ & $0.42(-0.61$ to 1.45$)$ & 0.463 \\
\hline Change in Trails B score, seconds & $10.92(6.03$ to 15.80$)$ & $2.96(-6.46$ to 12.38$)$ & 0.130 & 10.66 (5.93 to 15.38$)$ & $1.43(-9.47$ to 12.38$)$ & 0.117 \\
\hline Rate of change Trails B score & 1.26 (0.68 to 1.84$)$ & 0.18 (-0.97 to 1.32$)$ & 0.084 & $1.22(0.66$ to 1.78$)$ & -0.0097 (-1.39 to 1.32) & 0.081 \\
\hline
\end{tabular}

Table 4. Unadjusted and adjusted odds ratios for substantial cognitive decline for all participants according to systolic inter-arm blood pressure difference

\begin{tabular}{|c|c|c|c|c|c|c|c|c|}
\hline \multirow[b]{2}{*}{ Cognitive measure } & \multicolumn{4}{|c|}{$I A D \geq 5 \mathrm{mmHg}$} & \multicolumn{4}{|c|}{$I A D \geq 10 \mathrm{mmHg}$} \\
\hline & $\begin{array}{l}\text { Unadjusted OR } \\
\text { (95\% CI) }\end{array}$ & $P$-value & $\begin{array}{l}\text { Adjusted }^{\mathrm{O}} \mathrm{R} \\
(95 \% \mathrm{CI})\end{array}$ & $P$-value & $\begin{array}{c}\text { Unadjusted OR } \\
(95 \% \mathrm{CI})\end{array}$ & $P$-value & $\begin{array}{c}\text { Adjusted }^{2} \text { OR } \\
(95 \% \mathrm{Cl})\end{array}$ & $P$-value \\
\hline MMSE & 1.41 (1.03 to 1.93) & 0.032 & 1.31 (0.91 to 1.88 ) & 0.140 & 1.30 (0.92 to 1.83 ) & 0.142 & 1.07 (0.72 to 1.60$)$ & 0.740 \\
\hline Trails A & 1.17 (0.80 to 1.70) & 0.415 & 1.10 (0.71 to 1.73 ) & 0.663 & 1.24 (0.82 to 1.86$)$ & 0.305 & 1.05 (0.64 to 1.74 ) & 0.833 \\
\hline Trails B & 1.30 (0.94 to 1.79 ) & 0.112 & 1.23 (0.80 to 1.89$)$ & 0.344 & 1.27 (0.89 to 1.83 ) & 0.192 & 1.06 (0.66 to 1.73 ) & 0.800 \\
\hline Composite outcome & 1.44 (1.10 to 1.89 ) & 0.009 & 1.46 (1.05 to 2.03 ) & 0.026 & 1.39 (1.03 to 1.88 ) & 0.030 & 1.23 (0.85 to 1.78 ) & 0.265 \\
\hline
\end{tabular}

${ }^{a}$ Adjusted for age, sex, baseline MMSE score, years in education, systolic blood pressure, ankle-brachial index, presence of diabetes, previous cerebrovascular event, and duration of follow-up. $\mathrm{Cl}=$ confidence interval. $I A D=$ systolic inter-arm blood pressure difference. MMSE = mini mental state examination. OR=odds ratio. Trails $=$ Trail Making Tests.

\section{Table 5. Multivariable models used to adjust associations of cognitive decline measures with inter-arm difference}

\begin{tabular}{lccccr} 
& \multicolumn{2}{c}{ Decline in MMSE score $\geq 5$} & & \multicolumn{2}{c}{ Composite outcome } \\
\cline { 2 - 3 } \cline { 5 - 6 } Variable & $\mathbf{O R}$ & $\boldsymbol{P}$-value & & $\mathbf{O R}$ & $\boldsymbol{P}$-value \\
\hline Age & 1.09 & $<0.001$ & & 1.07 & $<0.001$ \\
\hline Sex & 1.20 & 0.267 & 1.35 & 0.037 \\
\hline Baseline MMSE & 1.02 & 0.617 & 0.94 & 0.050 \\
\hline Years in education & 0.91 & 0.003 & 0.90 & $<0.001$ \\
\hline Systolic blood pressure & 1.01 & 0.235 & 1.00 & 0.980 \\
\hline Ankle-brachial index & 1.58 & 0.397 & 0.52 & 0.184 \\
\hline Diabetes & 1.49 & 0.068 & 1.96 & 0.002 \\
\hline Previous cerebrovascular event & 2.22 & 0.020 & 1.53 & 0.231 \\
\hline Duration of follow-up & 1.02 & $<0.001$ & 1.02 & $<0.001$
\end{tabular}

aVariables dropped from models on backward stepwise regression: baseline cardiovascular disease; baseline diastolic blood pressure; hypercholesterolaemia; smoking status; body mass index; and carotid stenosis $\geq 40 \%$. MMSE = mini mental state examination. $O R=$ odds ratio a simultaneous method, and the pause between measurements may have augmented differences because of white coat effects. ${ }^{10,31}$ There was also evidence of rounding of blood pressure readings, which can contribute to measurement error through digit preference. ${ }^{32}$ Nevertheless, these limitations make the blood pressure readings analogous to routine clinical measurements, and the prognostic value of IAD derived from sequential measurements in other studies has not differed significantly from that of simultaneous measurements. ${ }^{8,13}$ To minimise the impact of test-to-test variability in cognitive assessments, valid criteria for a substantial reduction in cognition over time were adopted, and outcomes were adjusted for duration of follow-up. ${ }^{25-27}$ The composite measure for cognitive decline has been reported from cross-sectional work, ${ }^{28}$ but, to the authors' knowledge, it has not previously been reported in prospective analyses such as is presented here.

The InCHIANTI cohort is representative of an older Italian population lexcepting those aged $\geq 90$ years). ${ }^{33}$ Ethnic differences in the aetiology and prognostic importance of IAD may exist, ${ }^{13,34}$ but this is uncertain..$^{31}$ 
Consequently, the authors are cautious of extrapolating these findings to other ethnic groups. Rising risks of cognitive decline with increasing magnitude of IAD were not observed. Previous individual studies and study-level meta-analyses have also failed to show a positive correlation between size of hazard ratios for prospective mortality outcomes and magnitude of IAD, 8,12 although this has recently been shown in the authors' large (>57 000 records) individual participant data meta-analysis published in $2018 .{ }^{13}$ The present study had few people $(<3 \%)$ with an IAD $\geq 15 \mathrm{mmHg}$; it lacked power to explore IADs above the $\geq 10 \mathrm{mmHg}$ threshold, and the sample size available for this study was too small to demonstrate trends in risk according to level of IAD. The limitations in measurement technique discussed above could also have contributed to the differences in associations seen between $5 \mathrm{mmHg}$ and $10 \mathrm{mmHg}$ IAD cut-offs.

In presenting analyses of four cognitive outcomes, there is a risk of spurious associations being observed by chance alone. A conservative approach to interpretation, taking account of a Bonferron correction, would apply a $P$-value of 0.0125 as an appropriate threshold for significance testing. While none of the adjusted findings met this level of significance, all of the odds ratios presented are consistent in direction (that is, $>1.0$ ), suggesting that IAD may be associated with cognitive decline, but this study was limited in power las evidenced by the wide confidence intervals observed) to demonstrate such associations. Because of limitations of the data, the authors could not take account of the introduction of drugs for dementia during the study; however, only $1 \%$ of the cohort reported use of such drugs at follow-up, indicating a low likelihood of impact on the findings.

\section{Comparison with existing literature}

IADs have been observed in both crosssectional and prospective studies to be associated with higher incidences of allcause mortality, stroke, and cerebral arterial stenoses. ${ }^{8,35-37} \mathrm{An}$ increasing pulse pressure is also associated with both magnitude of IAD and magnetic resonance imaging evidence of markers for dementia risk. 9,34,38 Therefore, an association of IAD with cognitive decline is plausible given these vascular associations, as a result of vascular stiffening. 4.39 However, only one previous longitudinal cohort study has examined this; using data from the Framingham Heart Study, investigators found an association of IAD with cognitive decline restricted to the subgroup of participants possessing the apolipoprotein E $\varepsilon 4$ allele. ${ }^{21}$ One other study has reported an association between differences in ankle artery pressures and greater decline in a composite cognitive score in people with diabetes. ${ }^{28}$ Consequently, the authors believe that the current study presents the first data to associate an IAD in blood pressure with cognitive decline in a general cohort representative of an older age community population.

Given the absence of effective treatments to date for established dementia, current emphasis is on prevention and reduction of cognitive decline..$^{19}$ Intensive blood pressure lowering may be effective but is not a riskfree strategy; therefore, recognition of novel cardiovascular risk markers to refine risk prediction and stratify treatment priorities is important. ${ }^{40}$ IAD is one such easily measured risk marker, associated with arterial stiffening and elevated pulse wave velocity, thus indicating an increased risk of target organ damage at an early stage. ${ }^{41}$ The addition of non-invasive assessments of target organ damage can reclassify individuals with such risk markers present into higher-risk groups. ${ }^{42}$ The present findings require confirmation in other populations but, if they are reproducible, then IAD measurement may offer an opportunity to identify, at a preclinical stage, those people most likely to benefit from aggressive preventive strategies. ${ }^{20}$

\section{Implications for research and practice}

Recommendations to initially check blood pressure in both arms are included in international hypertension guidelines. ${ }^{43,44}$ Uptake of bilateral measurement may be increasing, and this can be facilitated by providing clinicians with evidence about the implications of an IAD.45.46 The 2019 National Institute for Health and Care Excellence hypertension guidelines ${ }^{44}$ have reduced their suggested threshold for a significant IAD from $20 \mathrm{mmHg}$ to $15 \mathrm{mmHg}$. Other evidence suggests that an IAD $<5 \mathrm{mmHg}$ can be considered a normal finding, while excess cardiovascular events and deaths start to be observed above this threshold. 13,47-49 The present study findings provide initial evidence to add cognitive decline to these outcomes at the same threshold, while suggesting that people with an IAD $<5 \mathrm{mmHg}$ can be reassured. Awareness of the evidence around IAD can inform discussion of individual interventions to address modifiable risk factors and improve primary prevention of cardiovascular diseases. An IAD is easily checked without additional equipment or 
skills. While simultaneous measurement might be recommended in the guidelines, there is substantial evidence to demonstrate the prognostic associations of sequentially measured IADs obtained in practice. ${ }^{13,43}$

Intensive blood pressure lowering may reduce the progression of cognitive impairment, but it is not without risk. ${ }^{19}$ Such regimens are consistently associated with more frequent adverse events such as acute kidney injury, hypotension, falls, and fractures. ${ }^{50-53}$ Thus, there is a trade-off between reducing the risks of events and increasing the risks of adverse events; this implies the need to personalise treatments by addressing risk markers for individuals. ${ }^{54}$ The current findings lacked power because of sample size limitations so further research in larger populations is warranted. Confirmation of IAD as a risk marker for future cognitive decline could, in the future, enable clinicians to target intensification of treatment at those most at risk to reduce their risk of cognitive decline and dementia.

\section{Funding}

Christopher E Clark was supported by a National Institute for Health Research (NIHR) Clinical Lectureship award. David J Llewellyn is supported by the James Tudor Foundation, the Mary Kinross Charitable Trust, the Halpin Trust, the NIHR Collaboration for Leadership in Applied Health Research and Care for the South West Peninsula, and the National Institute on Aging/National Institutes of Health (NIA) $\mathrm{NIH)}$ under award number RF1AG055654, and the Alan Turing Institute under the Engineering and Physical Sciences Research Council grant EP/N510129/1. This work was supported in part by the Intramural Research Program of the NIA/NIH, Baltimore MD, US. The views expressed are those of the authors and not necessarily those of the NIHR, the NHS, or the Department of Health and Social Care.

\section{Ethical approval}

Ethical approval for the InCHIANTI study was provided by the Italian National Research Council on Aging Ethical Committee.

\section{Provenance}

Freely submitted; externally peer reviewed.

\section{Competing interests}

The authors have declared no competing interests.

\section{Discuss this article}

Contribute and read comments about this article: bjgp.org/letters 


\section{REFERENCES}

1. Emdin CA, Anderson SG, Callender T, et al. Usual blood pressure, peripheral arterial disease, and vascular risk: cohort study of 4.2 million adults. BMJ 2015; 351: h4865.

2. Naghavi M, Wang HD, Lozano R, et al. Global, regional, and national age-sex specific all-cause and cause-specific mortality for 240 causes of death, 1990 2013: a systematic analysis for the Global Burden of Disease Study 2013. Lancet 2015; 385(9963): 117-171.

3. World Health Organization. Dementia: a public health priority. 2012. https:// www.who.int/mental_health/publications/dementia_report_2012/en laccessed 11 Mar 2020).

4. Emdin CA, Rothwell PM, Salimi-Khorshidi G, et al. Blood pressure and risk of vascular dementia: evidence from a primary care registry and a cohort study of transient ischemic attack and stroke. Stroke 2016; 47(6): 1429-1435.

5. Rouch L, Cestac P, Hanon O, et al. Blood pressure and cognitive performances in middle-aged adults: the Aging. Health and Work longitudinal study. $J$ Hypertens 2019; 37(6): 1244-1253.

6. Xu W, Qiu C, Gatz M, et al. Mid- and late-life diabetes in relation to the risk of dementia: a population-based twin study. Diabetes 2009; 58(1): 71-77.

7. Qiu C, Winblad B, Viitanen M, Fratiglioni L. Pulse pressure and risk of Alzheimer disease in persons aged 75 years and older: a community-based, longitudinal study. Stroke 2003; 34(3): 594-599.

8. Clark CE, Taylor RS, Shore AC, et al. Association of a difference in systolic blood pressure between arms with vascular disease and mortality: a systematic review and meta-analysis. Lancet 2012; 379(9819): 905-914.

9. Canepa M, Milaneschi Y, Ameri P, et al. Relationship between inter-arm difference in systolic blood pressure and arterial stiffness in communitydwelling older adults. J Clin Hypertens 2013; 15(12): 880-887.

10. Clark CE, Taylor RS, Shore AC, Campbell JL. Prevalence of systolic inter-arm differences in blood pressure varies for different primary care populations: systematic review and meta-analysis. Br J Gen Pract 2016; DOI: https://doi. org/10.3399/bjgp16X687553.

11. Giles TD. Inter-arm difference in systolic blood pressure - 'the plot stiffens' $J$ Clin Hypertens 2013; 15(12): 878-879.

12. Cao K, Xu J, Shangguan $Q$, et al. Association of an inter-arm systolic blood pressure difference with all-cause and cardiovascular mortality: an updated meta-analysis of cohort studies. Int J Cardiol 2015; 189: 211-219.

13. Clark C, Boddy K, Warren F, et al. Inter-arm differences in blood pressure and mortality: individual patient data meta-analysis and development of a prognostic algorithm (INTERPRESS-IPD COLLABORATION). Can J Cardiol 2018; 34(10 Suppl 1): S131

14. Williams B. Hypertension in the young: preventing the evolution of disease versus prevention of clinical events. J Am Coll Cardiol 2007; 50(9): 840-842.

15. de Roos A, van der Grond J, Mitchell G, Westenberg J. Magnetic resonance imaging of cardiovascular function and the brain: is dementia a cardiovasculardriven disease? Circulation 2017; 135(22): 2178-2195.

16. Benedictus MR, van Harten AC, Leeuwis AE, et al. White matter hyperintensities relate to clinical progression in subjective cognitive decline. Stroke 2015; 46(9): 2661-2664

17. Yasar S, Xia J, Yao W, et al. Ginkgo Evaluation of Memory (GEM) Study Investigators. Antihypertensive drugs decrease risk of Alzheimer disease: Ginkgo Evaluation of Memory Study. Neurology 2013; 81(10): 896-903.

18. Verhaaren BFJ, Vernooij MW, de Boer R, et al. High blood pressure and cerebral white matter lesion progression in the general population. Hypertension 2013; 61(6): $1354-1359$.

19. Williamson JD, Pajewski NM, Auchus AP, et al. SPRINT MIND Investigators for the SPRINT Research Group. Effect of intensive vs standard blood pressure control on probable dementia: a randomized clinical trial. JAMA 2019: 321(6): 553-561.

20. Solomon A, Soininen H. Dementia: risk prediction models in dementia prevention. Nat Rev Neurol 2015; 11(7): 375-377.

21. Pase MP, Beiser A, Aparicio H, et al. Interarm differences in systolic blood pressure and the risk of dementia and subclinical brain injury. Alzheimers Dement 2016; 12(4): 438-445.

22. Ferrucci L, Bandinelli S, Benvenuti E, et al. Subsystems contributing to the decline in ability to walk: bridging the gap between epidemiology and geriatric practice in the InCHIANTI study. J Am Geriatr Soc 2000; 48(12): 1618-1625.
23. Reitan RM. Validity of the Trail Making Test as an indicator of organic brain damage. Percept Mot Skills 1958; 8(3): 271-276.

24. Folstein MF, Folstein SE, McHugh PR. 'Mini-mental state'. A practical method for grading the cognitive state of patients for the clinician. J Psychiatr Res 1975; 12(3): 189-198.

25. Schmand B, Lindeboom J, Launer $L$, et al. What is a significant score change on the mini-mental state examination? Int J Geriatr Psychiatry 1995; 10(5): 411-414.

26. Littlejohns TJ, Kos K, Henley WE, et al. Serum leptin and risk of cognitive decline in elderly Italians. J Alzheimers Dis 2015; 44(4): 1231-1239.

27. Llewellyn DJ, Lang IA, Langa KM, et al. Vitamin $D$ and risk of cognitive decline in elderly persons. Arch Intern Med 2010; 170(13): 1135-1141.

28. Espeland MA, Beavers KM, Gibbs BB, et al. Ankle-brachial index and interartery blood pressure differences as predictors of cognitive function in overweight and obese older adults with diabetes: results from the Action for Health in Diabetes movement and memory study. Int J Geriatr Psych 2015; 30(10): 999-1007.

29. Clark CE, Boddy K, Warren FC, et al. Associations between interarm differences in blood pressure and cardiovascular disease outcomes: protocol for an individual patient data meta-analysis and development of a prognostic algorithm. BMJ Open 2017; 7(6): e016844.

30. Tombaugh TN. Test-retest reliable coefficients and 5-year change scores for the MMSE and 3MS. Arch Clin Neuropsychol 2005; 20(4): 485-503.

31. Schwartz CL, Clark C, Koshiaris $C$, et al. Interarm difference in systolic blood pressure in different ethnic groups and relationship to the 'white coat effect': a cross-sectional study. Am J Hypertens 2017; 30(9): 884-891.

32. Kallioinen N, Hill A, Horswill MS, et al. Sources of inaccuracy in the measurement of adult patients' resting blood pressure in clinical settings: a systematic review. J Hypertens 2017; 35(3): 421-441.

33. Clark CE, Thomas D, Warren FC, et al. Detecting Risks Of Postural hypotension (DROP): derivation and validation of a prediction score for primary care. BMJ Open 2018; 8(4): e020740.

34. Clark C, Warren F, Boddy K, et al. Inter-arm blood pressure difference: insights into aetiology from the INTERPRESS-IPD COLLABORATION. J Hypertens 2019; 37(Suppl 1): e34.

35. Kim JY, Kim EJ, Namgung J, et al. Between-visit reproducibility of interarm systolic blood pressure differences in treated hypertensive patients: the CoCoNET study. Hypertens Res 2017; 40(5): 483-486.

36. Wang Y, Zhang J, Qian Y, et al. Association of inter-arm blood pressure difference with asymptomatic intracranial and extracranial arterial stenosis in hypertension patients. Sci Rep 2016; 6: 29894

37. Kranenburg G, Spiering W, de Jong PA, et al. Inter-arm systolic blood pressure differences, relations with future vascular events and mortality in patients with and without manifest vascular disease. Int J Cardiol 2017; 244: 271-276.

38. Cox SR, Lyall DM, Ritchie SJ, et al. Associations between vascular risk factors and brain MRI indices in UK Biobank. Eur Heart J 2019; 40(28): 2290-2300.

39. Mitchell GF, van Buchem MA, Sigurdsson S, et al. Arterial stiffness, pressure and flow pulsatility and brain structure and function: the Age, Gene/ Environment Susceptibility - Reykjavik study. Brain 2011; 134(Pt 11): 33983407

40. Simon A, Levenson J. May subclinical arterial disease help to better detect and treat high-risk asymptomatic individuals? J Hypertens 2005; 23(11): 1939-1945.

41. Tomiyama H, Ohkuma T, Ninomiya T, et al. Simultaneously measured interarm blood pressure difference and stroke: an individual participants data metaanalysis. Hypertension 2018; 71(6): 1030-1038.

42. Abellán-Huerta J, Prieto-Valiente L, Consuegra-Sánchez L. Most advisable strategy in search of asymptomatic target organ damage in hypertensive patients. Hipertens Riesgo Vasc 2017; 34(4): 149-156.

43. Williams B, Mancia G, Spiering W, et al. ESC Scientific Document Group. 2018 ESC/ESH guidelines for the management of arterial hypertension. Eur Heart $J$ 2018; 39(33): 3021-3104

44. National Institute for Health and Care Excellence. Hypertension in adults: diagnosis and management. NG136. London: NICE, 2019. https://www.nice.org. uk/guidance/ng136 (accessed 11 Mar 2020)

45. Mejzner N, Clark CE, Smith LF, Campbell JL. Trends in the diagnosis and management of hypertension: repeated primary care survey in South West England. Br J Gen Pract 2017; DOI: https://doi.org/10.3399/bjgp17X690461. 
46. Parker E, Glasziou P. Use of evidence in hypertension guidelines: should we measure in both arms? Br J Gen Pract 2009; DOI: https://doi.org/10.3399/ bjgp09X395012.

47. Clark CE, Taylor RS, Butcher I, et al. Inter-arm blood pressure difference and mortality: a cohort study in an asymptomatic primary care population at elevated cardiovascular risk. Br J Gen Pract 2016; DOI: https://doi.org/10.3399/ bjgp16X684949.

48. Hirono A, Kusunose K, Kageyama N, et al. Development and validation of optimal cut-off value in inter-arm systolic blood pressure difference for prediction of cardiovascular events. J Cardiol 2018; 71(1): 24-30.

49. White J, Mortensen LH, Kivimäki M, et al. Interarm differences in systolic blood pressure and mortality among US army veterans: aetiological associations and risk prediction in the Vietnam Experience Study. Eur J Prev Cardiol 2014; 21(11): 1394-1400
50. Wright JT Jr, Williamson JD, Whelton PK, et al. SPRINT Research Group. A randomized trial of intensive versus standard blood-pressure control. N Engl Med 2015; 373(22): 2103-2116.

51. Cushman WC, Evans GW, Byington RP, et al. ACCORD Study Group. Effects of intensive blood-pressure control in type 2 diabetes mellitus. N Engl J Med 2010; 362(17): 1575-1585.

52. Clark CE, McManus R. The use of highly structured care to achieve blood pressure targets. BMJ 2012; 345: e7777.

53. Butt DA, Mamdani M, Austin PC, et al. The risk of hip fracture after initiating antihypertensive drugs in the elderly. Arch Intern Med 2012; 172(22): 1739 1744

54. Patel KK, Arnold SV, Chan PS, et al. Personalizing the intensity of blood pressure control: modeling the heterogeneity of risks and benefits from SPRINT (Systolic Blood Pressure Intervention Trial). Circ Cardiovasc Qual Outcomes 2017; 10(4). 